Sharif University of Technology
Scientia Iranica
Transactions E: Industrial Engineering
http://scientiairanica.sharif.edu

\title{
Forecasting and making policies for postal services: System dynamics approach (Iran Post Company as a case study)
}

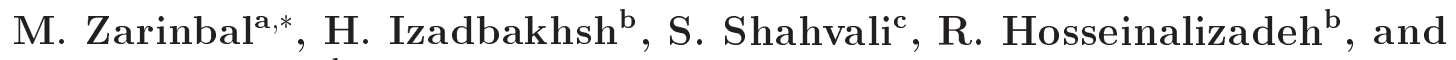 \\ F. ZadehLabaf ${ }^{\mathrm{d}}$ \\ a. Iranian Research Institute for Information Science and Technology (IranDoc), Tehran, Iran. \\ b. Department of Industrial Engineering, Faculty of Engineering, Kharazmi University, Tehran, Iran. \\ c. Department of Industrial Management and Information Technology, Management and Accounting Faculty, Shahid Beheshti \\ University, G.C., Tehran, Iran. \\ d. Department of Statistics, Mathematics, Science Faculty, University of Isfahan, Isfahan, Iran.
}

Received 15 May 2019; received in revised form 24 November 2019; accepted 4 January 2020

\section{KEYWORDS \\ System dynamics approach; \\ Forecasting; \\ Scenario planning; \\ Postal services; \\ Iran post company.}

\begin{abstract}
The main objective of postal services is to deliver letter mails and parcels. By changing customers' needs and behaviors along with emerging new technologies, postal services have to be renovated. Thus, understanding the changing environment, forecasting the performance, identifying key drivers, and making effective interventions are critical to any further actions. Performing these actions for Iran Post Company is the focus of this paper. Therefore, system dynamic approach is chosen, effective variables are determined, and Causal-Loop Diagram (CLD) and Stock-to-Flow Diagram (SFD) are developed. The results are then validated using expert panels and historical data, and the developed model is utilized for policy making. Therefore, two scenarios are designed based on changes in postal rates, quality of services, and e-service market share. These scenarios could provide CEOs with critical information to make effective interventions.
\end{abstract}

(C) 2021 Sharif University of Technology. All rights reserved.

\section{Introduction}

Delivering letter mails and parcels remains the main activity of postal services and for more than 200 years, postal service has fulfilled its mission. However, the market is changing rapidly along with the customers'

\footnotetext{
*. Corresponding author. Tel.: +982166494980

E-mail addresses: zarinbal@irandoc.ac.ir (M. Zarinbal); hizadbakhsh@khu.ac.ir (H. Izadbakhsh); salman.shahvali@gmail.com (S. Shahvali); ramin.h_alizadeh@yahoo.com (R. Hosseinalizadeh); faribalabbaf@yahoo.com (F.ZadehLabaf)
}

needs and desires. In these conditions, providing new services, allocating resources, estimating performance, planning for future, and making policies could be challenging. To overcome these challenges, forecasting is essential [1].

To predict the future forecasting, various methods have been developed such as time series [2-4], econometrics [5-7], artificial intelligence [8-10], grey forecasting model [11-13], and simulation [14-16] and among them, econometrics is the most common one. However, econometrics suffer from some limitations, i.e., the true model for any given data is unknown and the formulated model depends on static parameters that need to be estimated from data [17]. Hence, 
using this method for forecasting a complex system with changing states over time, such as postal service, would be inefficient. More specifically, aging dynamics, immigration, emerging new technologies and services along with emerging new postal operators (competitors), and changes in customers' desires affect the postal companies' environment.

Simulation, on the other hand, is widely used in dynamic situations to understand and estimate the real behavior of the system over time. System Dynamics (SD) is a macro simulation technique introduced by J.W. Forester in $1960 \mathrm{~s}$ and it considers the system as a set of loops to determine its dynamics and to find dynamic behavior through time. This behavior is (re)created by tracking the changes in the values of stocks and flows over time and by mapping information transfers among them [18]. SD with the purpose of forecasting and policy making has been used in many applications such as [19-25].

Understanding the postal environment and forecasting postal services performance over the time are the main concerns in this paper. Thus, Iran Post Company is selected as a case study and its most important performance indicators, traffic, revenue, and cost are analyzed. Iran has a long history of providing postal services and is one of the world pioneers. This company connects more than 29,000 destinations worldwide and transports more than 3 million letter mails and parcels a day [26]. In other words, the focus of this paper is to understand Iran postal environment, forecast the performance of Iran Post Company, and provide a tool for making policies. This is done using SD approach during which the inner and outer environments of the company are analyzed and an integrated model is developed.

That is, first, the variables generating mail demands in the outer environment of company are modeled. Determining and modeling the variables helping the company to absorb the mail demands is the next step. These variables are the ones defined in inner environment of company. These two separate models are then integrated into a simulation model and validated using various techniques such as comparing them with historical data and reviewing by expert panels. Two different scenarios are also designed to identify key drivers and define effective interventions. In the first scenario, the effects of price and quality of services on the selected indicators are assessed and in the second scenario, the effect of emerging a new operator and changing in e-commerce on the abovementioned indicators is analyzed. In order to make the developed model more user-friendly, a web-based User Interface (UI) is designed using Python programming language.

The organization of this paper is as follows: in Section 2, SD approach and its main tools are discussed and Section 3 is dedicated to the research methodology.
The designed scenarios and the corresponding discussions are provided in Section 4. Section 5 is dedicated to the designed UI. Conclusion and future works are presented in Section 6 .

\section{System dynamic approach}

$\mathrm{SD}$ is one of the most widely used simulation techniques and provides conceptual and quantitative tools to model and simulate complex systems with changing states over time. In SD, in order to model and visualize how different variables are interrelated and to represent the feedback structure of the system, Causal-Loop Diagram (CLD) for the given problem is used. This diagram consists of a set of variables connected to each other (from a cause to an effect) by arrows with assigned polarity to show the structure of the system. Positive link means that if the cause increases (decreases), the effect increases (decreases), and negative link means that if the cause increases (decreases), the effect decreases (increases). Thus, the main purpose of developing a CLD is to elicit and map the mental model of experts and participants about the problem at hand as well as its boundaries and the interrelated variables [27]. Figure 1 shows a simple CLD for collaboration between postal services and ecommerce. In this figure, "postal services demand" is the combination of online demand and offline demand. Therefore, growth in "internet penetration rate" could result in decreasing "postal services demand". On the other hand, this growth would result in increasing the "e-commerce sales". This increase would be amplified if post companies collaborate with e-commerce "post collaboration with e-commerce", appropriately. That is, by using appropriate polices in collaboration with e-commerce, the demand could experience a growth.

Testing and evaluating the developed CLD is the next step in SD, which is done using StockFlow Diagram (SFD). While CLD is an effective tool

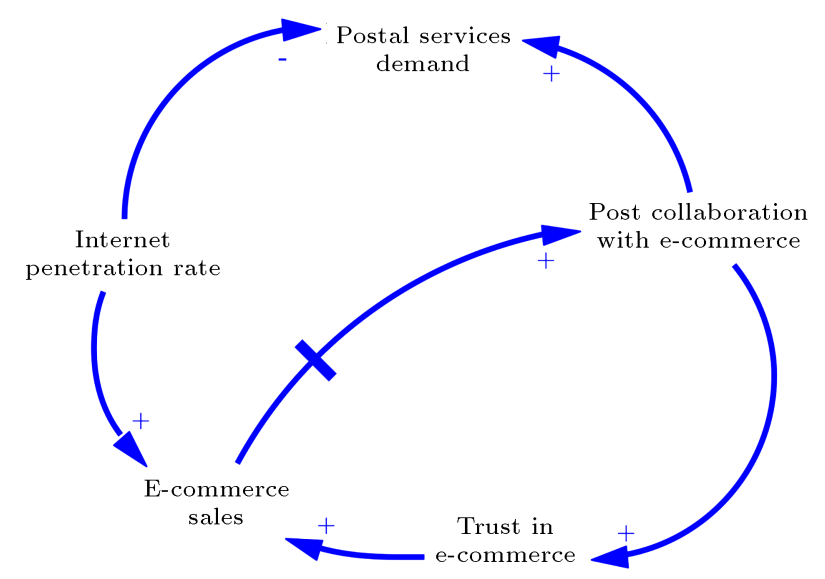

Figure 1. A simple Causal-Loop Diagram (CLD) for postal services. 
for representing interdependencies and feedbacks in a system, SFD is used to capture the physical structure of the system. In this diagram, stocks characterize the state of the system and generate the information upon which decisions and actions are based. Stocks also create delays and by decoupling rates of flow, they are the source of disequilibrium dynamics in systems [27].

In sum, in SD, first, a CLD is developed to map the experts' mentality about the problem at hand and then, SFD is developed to test and evaluate this mental model. SFD also provides a valuable tool for making policies. Structural and behavioral tests are then utilized to evaluate the developed SFD.

As mentioned before, this paper utilizes SD approach to forecast postal indicators and define effective interventions. The research methodology is discussed in the next section.

\section{Research methodology}

As indicated in [28], there are four basic steps in any forecasting study based on data:

1. Problem definition;

2. Information gathering and preliminary (exploratory) analysis;

3. Choosing and fitting forecasting method;

4. Simulating and evaluating.

In the first step, the problem along with its boundaries is defined and during the second step, by using historical data and expertise of key personnel, the needed data and information are gathered. Data processing methods are then applied to help the modeler to get a feel for data and find a class of models that might be useful in forecasting. Forecasting method is chosen and developed in the third step. Once a model has been developed and its parameters have been estimated, the model is simulated and evaluated using accuracy measures in the fourth step [28].

These steps required for forecasting the performance of Iran Post Company are given as follows.

\subsection{Step 1: Problem definition}

Based on the expertise of key personnel in Iran Post Company, the problem is defined as follows:
"Forecasting key forecasting indicators including traffic, revenue, and cost and making policies for the next 5 years".

For modeling this problem, the inner and outer environments of the company need to be analyzed. Upon analyzing the outer environment, the structure generating mail demand could be modeled and by analyzing the inner environment, the absorbing structure, which helps the company absorb the demands, could be developed. To do so, the influential variables related to these structures are divided into two categories: inner and outer variables. Figure 2 shows this idea. There are also common variables (both inner and outer) which are used to develop the integrated model.

To analyze the inner and outer environments and to determine variables, several researches such as $[7,9,29,30]$ have been studied and more than 10 expert panels are carried out to elicit experts' knowledge. Political, Economic, Social, and Technological (PEST) framework [31] is also utilized to analyze the outer environment. Some of the determined inner and outer variables are given below:

- Inner variables: Managerial decisions, revenue, expenditure, contracts, postal rates (tariff), customer satisfaction index, competitors, collaborative companies (domestic and international), mail delivery capacity, number of postal offices, number of staffs, staff satisfaction index, staff skills, quality of services, investment, new technologies, marketing, fleet capacity, and Information and Communications Technology (ICT) capacity.

\section{- Outer variables:}

- Political: regulation, privatization, ICT development policies;

- Economic: Gross Domestic Product (GDP), economic growth, per capita income, employment ratio, and agricultural, industrial and services units' added value;

- Social: population, population density, immigration, urbanization rate, tourism, student rate;

- Technological: ICT penetration rate, ICT development, e-commerce, e-government.

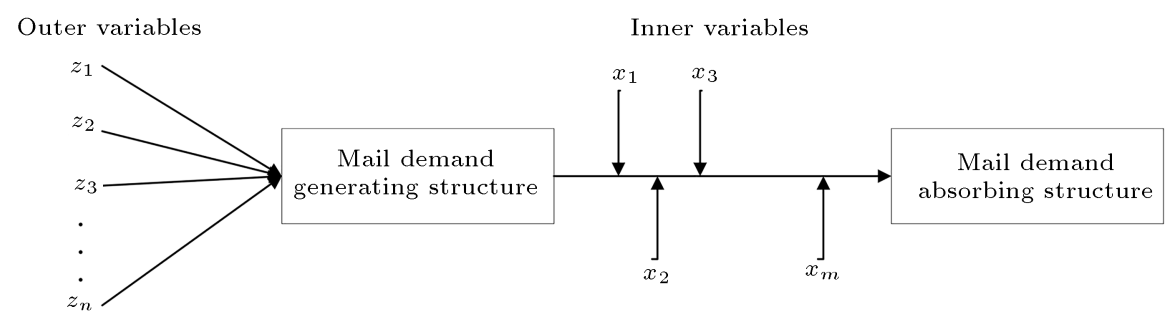

Figure 2. Problem definition; developing "mail demand generating structure" and "mail demand absorbing structure" by analyzing outer and inner variables. 


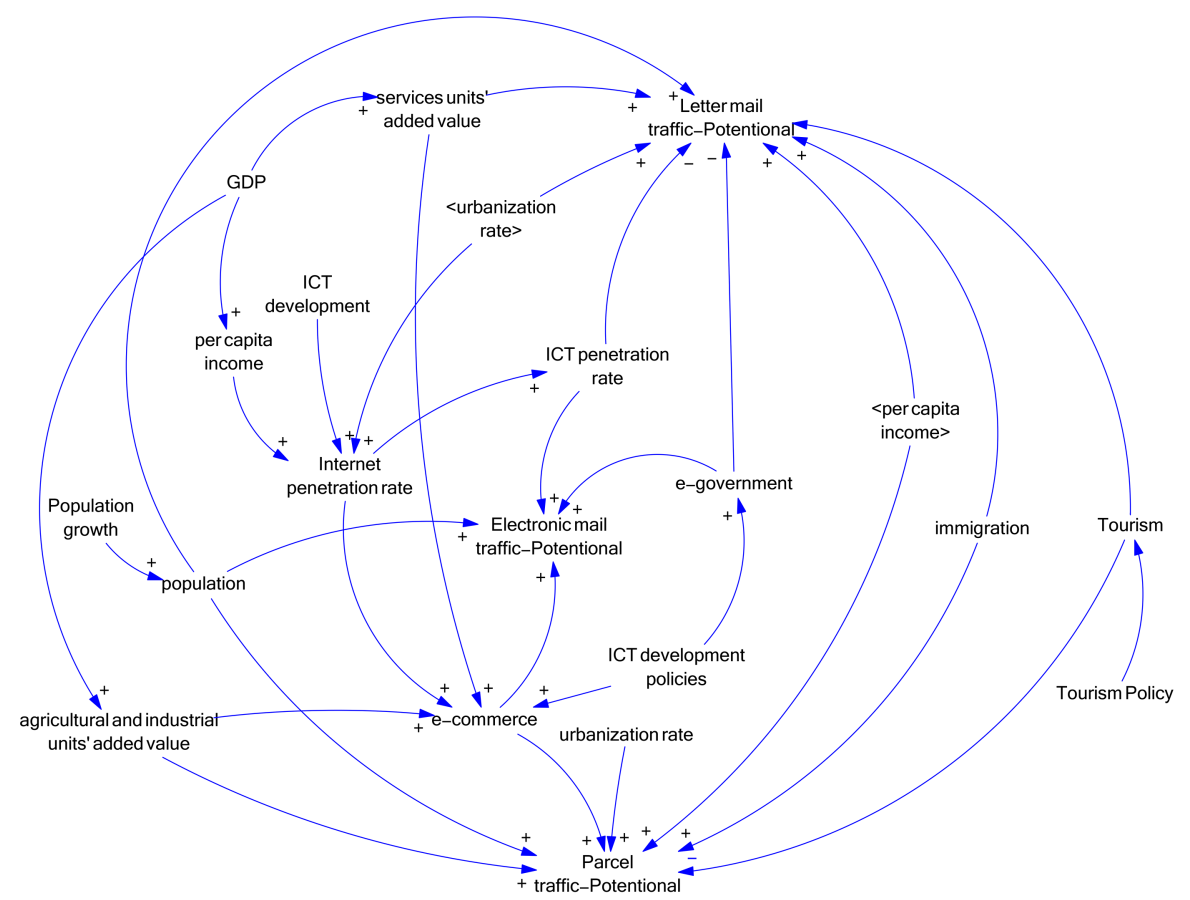

Figure 3. The main part of Causal-Loop Diagram (CLD) for the mail demand generating structure.

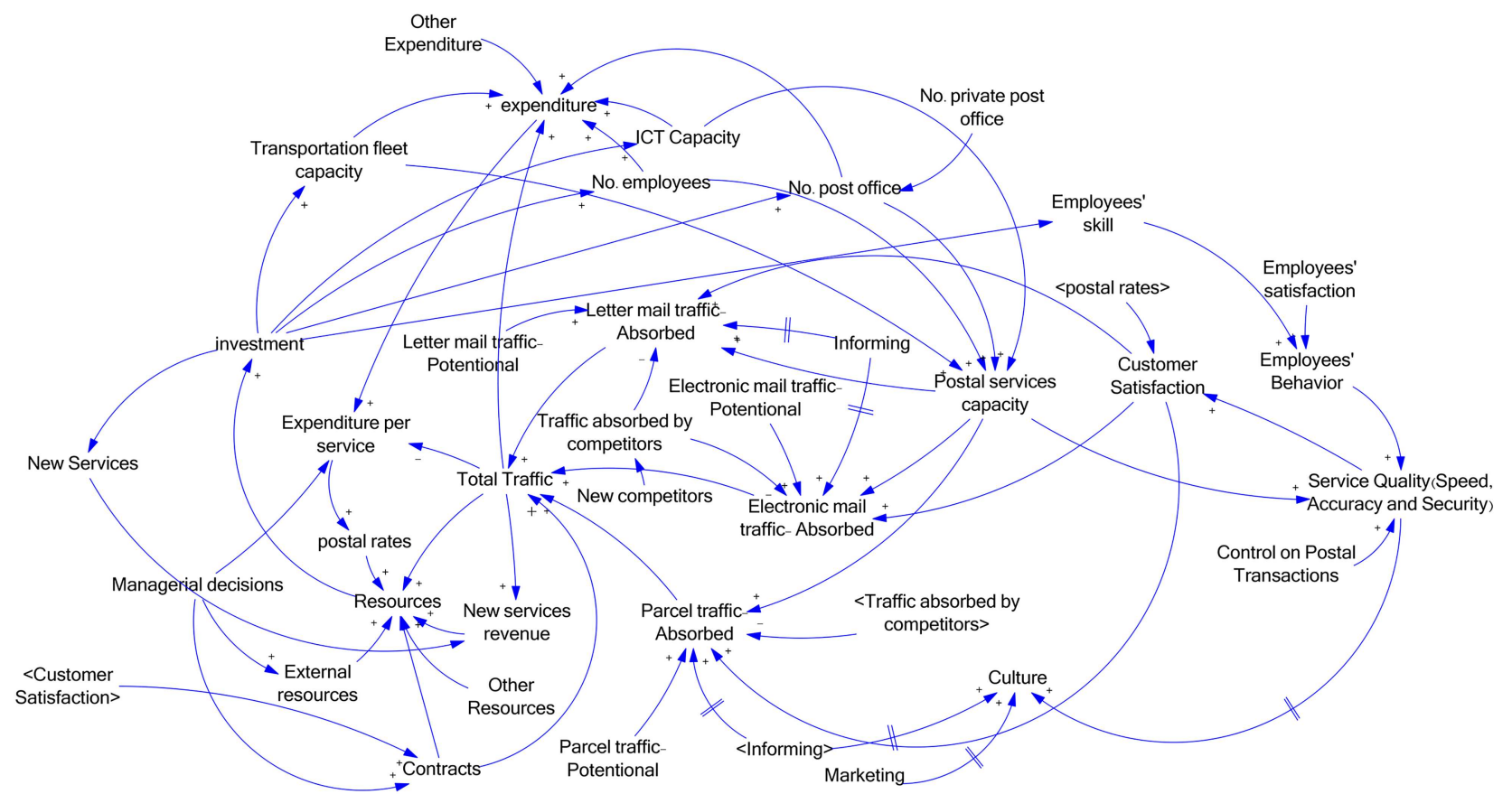

Figure 4. The main part of Causal-Loop Diagram (CLD) for the mail demand absorbing structure.

Using these variables, two CLDs are developed to demonstrate the generating and absorbing structures and are validated during several expert panels. Figures 3 and 4 demonstrate the main part of these CLDs.

To resolve the modeling problem, forecasting total traffic, total revenue, and total cost as three indicators should be calculated. Based on Figures 3 and 4, total traffic is constructed based on letter mail traffic, parcel traffic, and e-service traffic. That is, to forecast total traffic, letter mail traffic, parcel traffic, and e-service traffic should be added up. Likewise, to forecast total revenue, letter mail revenue, parcel revenue, and eservice revenue and to forecast total cost, letter mail cost, parcel cost, and e-service cost should be added up (Eq. (1)): 
Total traf fic $=$ Letter mail traf fic

$$
\begin{aligned}
& + \text { Parcel traffic } \\
& + \text { E- service traffic, }
\end{aligned}
$$

Total revenue $=$ Letter mail revenue

$$
\begin{aligned}
& + \text { Parcel revenue } \\
& + \text { E- service revenue, }
\end{aligned}
$$

Total cost $=$ Letter mail cost + Parcel cost

$$
+E-\text { service cost. }
$$

\subsection{Step 2: Information gathering and preliminary analysis}

The needed data about the aforementioned variables monitored for five years are gathered using the annual reports of Iran Post company as well as Iran plan and budget organization. Parts of data for outer and inner variables are reported in Tables 1 and 2, respectively.

\subsection{Step 3: Choosing and fitting forecasting method}

Based on the gathered data, preliminary analysis, and complexities demonstrated in Figures 3 and 4, SD approach is selected as the forecasting method and SFD is developed. This diagram is shown in Figure 5, in which the rectangles represent stock variables (accumulations of items) and the valves represent flow variables (the physical flows of items feeding into or depleting the stocks). Figure 5 consists of two parts, part A and B. While part A demonstrates the generating structure, the absorbing structure is shown in Part B. These structures are discussed in the following subsection.

\subsubsection{Mail demand generating structure}

\begin{tabular}{|c|c|c|c|c|c|c|c|c|c|c|c|c|c|}
\hline \multirow[b]{2}{*}{ Provenance } & \multicolumn{3}{|c|}{ Population $\left(10^{3}\right)$} & \multirow{2}{*}{$\begin{array}{l}\text { Urb. } \\
\text { rate }\end{array}$} & \multirow{2}{*}{$\begin{array}{l}\text { Stu. } \\
\text { rate }\end{array}$} & \multirow{2}{*}{$\begin{array}{c}\text { Emp. } \\
\text { rate }\end{array}$} & \multirow[b]{2}{*}{$\begin{array}{l}\text { Bir. }{ }^{4} \\
\text { rate }\end{array}$} & \multirow{2}{*}{$\begin{array}{c}\text { Per capita } \\
\text { income } \\
\left(10^{3}\right)\end{array}$} & \multicolumn{3}{|c|}{ Added value $\left(10^{6}\right)$} & \multirow{2}{*}{$\begin{array}{c}\text { ICT } \\
\text { penetration } \\
\text { rate }\end{array}$} & \multirow[b]{2}{*}{$\cdots$} \\
\hline & $<15$ & $15<<65$ & $>65$ & & & & & & $\begin{array}{l}\text { Ind. }^{5} \\
\text { units }\end{array}$ & $\begin{array}{l}\text { Agr. }^{6} \\
\text { units }\end{array}$ & $\begin{array}{l}\text { Ser. }{ }^{7} \\
\text { units }\end{array}$ & & \\
\hline ARD. & 290 & 8827 & 76 & 0.65 & 0.05 & 0.34 & 0.01 & 130 & 3 & 12 & 42 & 0.14 & $\cdots$ \\
\hline ESF. & 1023 & 3539 & 317 & 0.85 & 0.07 & 0.33 & 0.01 & 109 & 142 & 20 & 249 & 0.23 & $\ldots$ \\
\hline ALB. & 512 & 1785 & 116 & 0.90 & 0.04 & 0.31 & 0.03 & 115 & 32 & 8 & 115 & 0.22 & $\ldots$ \\
\hline IL. & 125 & 406 & 26 & 0.64 & 0.08 & 0.31 & 0.01 & 115 & 42 & 4 & 21 & 0.16 & $\cdots$ \\
\hline AZ.S. & 827 & 2635 & 263 & 0.69 & 0.03 & 0.18 & 0.01 & 97 & 32 & 18 & 111 & 0.16 & $\ldots$ \\
\hline AZ.G. & 779 & 2135 & 167 & 0.63 & 0.03 & 0.42 & 0.01 & 110 & 9 & 17 & 62 & 0.11 & $\ldots$ \\
\hline$\vdots$ & $\vdots$ & $\vdots$ & $\vdots$ & $\vdots$ & $\vdots$ & $\vdots$ & $\vdots$ & $\vdots$ & $\vdots$ & $\vdots$ & $\vdots$ & $\vdots$ & \\
\hline
\end{tabular}

Mail demand generating structure, as demonstrated in Figure 6, consists of three sections: population, economy, and ICT.

Table 1. Parts of data for "Outer variables" monitored for 5 years for each provenance.

\begin{tabular}{|c|c|c|c|c|c|c|c|c|c|c|c|c|c|}
\hline \multirow{2}{*}{ Provenance } & \multicolumn{5}{|c|}{ Revenue $\left(10^{9}\right)$} & \multicolumn{5}{|c|}{ Traffic $\left(10^{9}\right)$} & \multirow{2}{*}{$\begin{array}{c}\text { No. } \\
\text { employee }\end{array}$} & \multirow{2}{*}{$\begin{array}{l}\text { No. } \\
\text { offices }\end{array}$} & \multirow{2}{*}{$\cdots$} \\
\hline & 2012 & 2013 & 2014 & 2015 & 2016 & 2012 & 2013 & 2014 & 2015 & 2016 & & & \\
\hline ARD. & 8 & 30 & 38 & 53 & 59 & 3.35 & 7.17 & 4.06 & 5.19 & 5.02 & 186 & 94 & .. \\
\hline ESF. & 49 & 159 & 215 & 292 & 354 & 16.08 & 27.73 & 27.01 & 30.98 & 31.30 & 689 & 1048 & $\ldots$ \\
\hline ALB. & 30 & 138 & 169 & 249 & 271 & 8.10 & 14.56 & 18.85 & 14.29 & 13.92 & 425 & 174 & . \\
\hline IL. & 5 & 20 & 25 & 34 & 38 & 2.99 & 3.09 & 2.34 & 2.51 & 2.98 & 120 & 175 & \\
\hline AZ.S. & 20 & 98 & 1428 & 204 & 239 & 15.79 & 16.68 & 20.15 & 28.28 & 28.56 & 543 & 1182 & $\ldots$ \\
\hline AZ.G. & 25 & 69 & 83 & 108 & 135 & 8.80 & 15.13 & 18.56 & 15.81 & 15.16 & 320 & 857 & $\ldots$ \\
\hline$\vdots$ & $\vdots$ & $\vdots$ & $\vdots$ & $\vdots$ & $\vdots$ & : & : & $\vdots$ & : & : & : & $\vdots$ & \\
\hline
\end{tabular}

${ }^{1}$ : Urb.: Urbanization; ${ }^{2}$ : Stu.: Student; ${ }^{3}$ : Emp.: Employment; ${ }^{4}:$ Bir.: Birth; ${ }^{5}$ : Ind.: Industrial; ${ }^{6}$ : Agr.: Agricultural;

7: Ser.: Service.

Table 2. Parts of data for "Inner variables" monitored for 5 years for each provenance. 


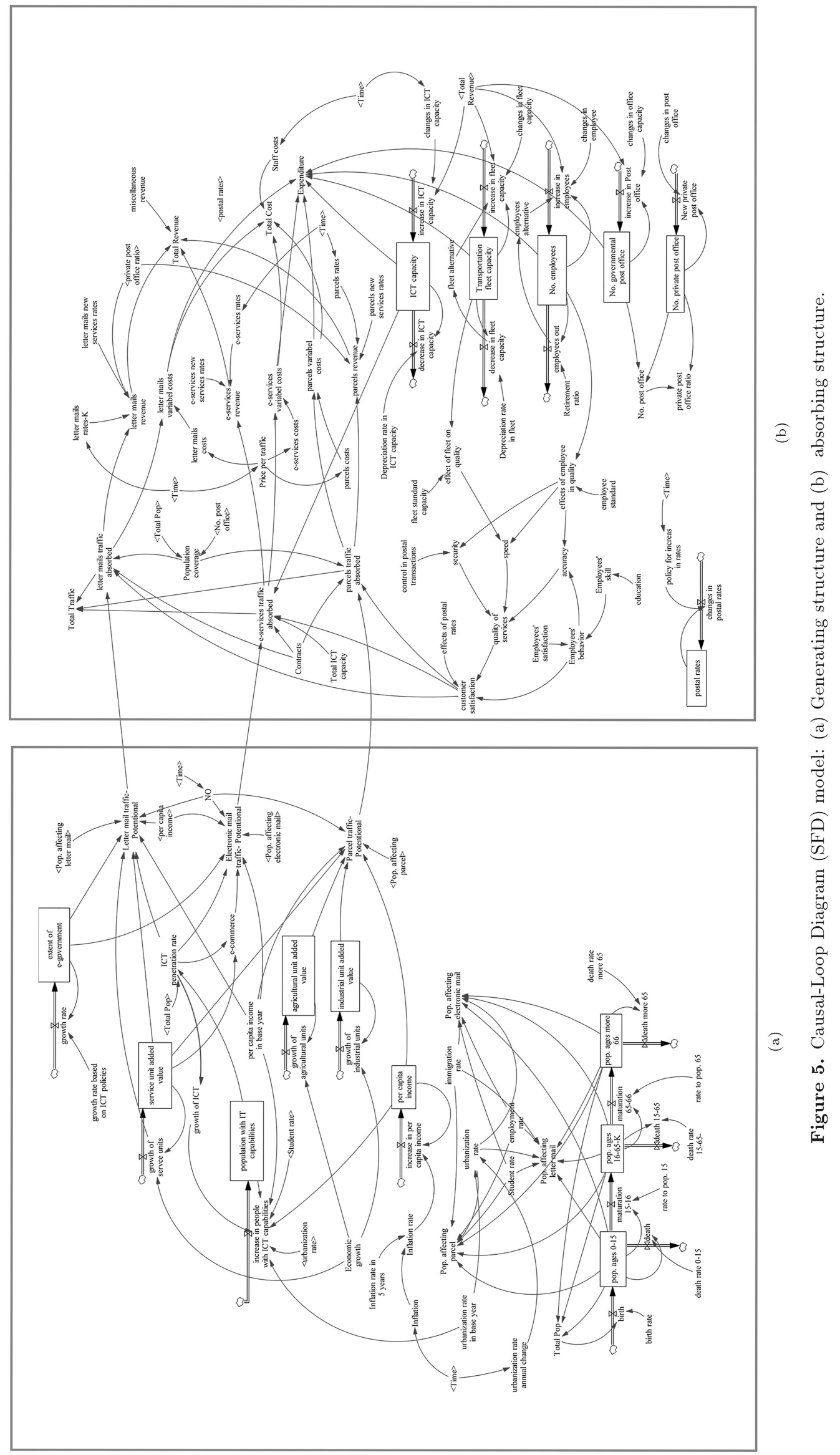




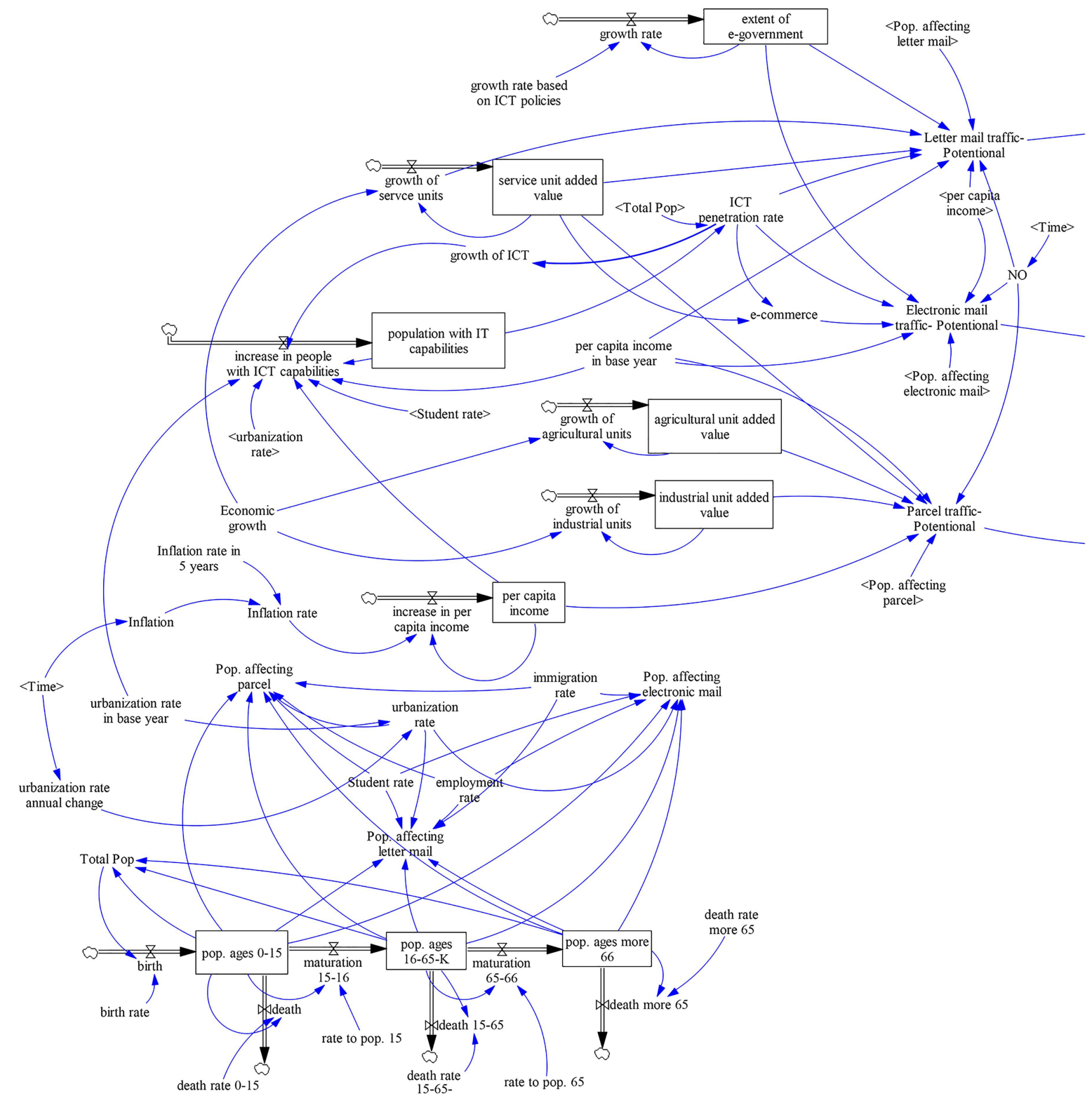

Figure 6. Mail demand generating structure (part A of Figure 5).

Aging chain is used to model population with three cohorts: "population ages 0-15", "population ages 16-56", and "population ages more than 66". "Birth rate", "death rate", and "maturation rates" are the flows.

The economy and ICT sections consist of 6 stocks: "per capita income", "population with ICT capabilities", "agricultural units' added value", "industrial units' added value", "services units' added value", and "extent of e-government".

Here, "population with ICT capacity" is calculated as:

Pop. with ICT capability

$$
=\frac{\text { urbanization rate }}{\text { urbanization rate base year }}
$$

$$
\begin{aligned}
& \times \frac{\text { per capita income }}{\text { per capita income base year }} \\
& \times \text { student rate } \times \text { growth of ICT } \\
& \times \text { people with ICT capability, }
\end{aligned}
$$

and "increase per capita income" is calculated in the same way as calculating per capita income growth:

Increase per capita income $=$ per capita income

$$
\times \text { inflation rate. }
$$

In addition, based on [32], Eq. (4), shown in Box I, is used to calculate the "growth of ICT": Based on [3335], the "Letter mail traffic-potential", "electronic 


$$
\text { Growth of ICT }= \begin{cases}12(1-I C T \text { penetration rate }) & \text { "ICT penetration rate" }<0.5 \\ 10(1-I C T \text { penetration rate }) & \text { "ICT penetration rate" }>0.5\end{cases}
$$

mail traffic-potential", and "parcel traffic-potential" are calculated using Eqs. (5)-(7):

Letter mail traffic-potential $=12$

$\times$ pop affecting letter mail

$\times(1+(-1.03 \times$ extent $e-$ government

$+0.337 \times I C T$ penetration rate +0.05

$\times \frac{\text { per capita income }}{\text { per capita income base year }}$

$\left.\left.+\frac{\text { growth service units }}{\text { service added value }}\right)\right)$,

Electronicmail traffic-potential

=pop affecting electronic mail

$\times(1+$ extent $e-$ government

+ ICT penetration rate

$\left.+\frac{\text { Per capita income }}{\text { Per capita income base year }}\right)$

$\times e-$ commerce,

Parceltraffic-potential

$$
\begin{aligned}
= & (\ln (\text { agricultural added value }) \\
& +\ln (\text { industrial added value }) \\
& +\ln (\text { service added value })) \\
& \times \text { pop. af fecting letter mail } \\
& \times\left(1+\frac{\text { per capita income }}{\text { per capita income base year }}\right)
\end{aligned}
$$

\subsubsection{Mail demand absorbing structure}

This structure is depicted in Figure 7. Investment, revenue, and expenditure and quality of services are three important sections in this structure. Developing and improving infrastructures such as "ICT capacity", "no. of employees", and "no. of governmental post offices" are the results of "total revenue" and "political decisions". These stocks along with "costs of letter mails and e-services and parcels" affect "expenditure". Total revenue is computed by adding up the "letter mails revenue", "e-services revenue", "parcels revenue", and "miscellaneous revenues".

On the other hand, the "transportation fleet infrastructures" affect the "quality of services", which is measured by three criteria: "accuracy", "speed", and "security". "Customer satisfaction" is the results of "quality", "employees' behavior", and "postal rates" and affects the "letter mail absorbed traffic", "e-services absorbed traffic", and "parcels absorbed traffic".

\subsection{Step 4: Simulating and evaluating}

As mentioned before, the developed SFD could be used for making policies, but before continuing to policy making, the model has to be simulated and evaluated. Historical data (from 2012 to 2016) and expert panels are used for this purpose. Structural and behavioral tests such as structural assessment, dimensional consistency, extreme conditions behavior reproduction, and sensitivity analysis [27] are also applied and the obtained results are validated by experts. The historical data (2012 to 2016) versus simulated data of the developed model for the three indicators, total traffic, total revenue, and total cost are reported in Figures 8-10, respectively.

To measure the accuracy, Mean Absolute Percentage Error (MAPE) [36] (Eq. (1)) is applied and the results, reported in Table 3 , show that the developed model is able to forecast the performance indicators, accurately.

Table 3. Mean Absolute Percentage Error (MAPE) results for $n=5$ and $n=3$.

\begin{tabular}{lcc}
\hline \multicolumn{1}{c}{ Indicator } & $\begin{array}{c}\text { MAPE for } \\
\boldsymbol{n}=\mathbf{5}\end{array}$ & $\begin{array}{c}\text { MAPE for } \\
\boldsymbol{n}=\mathbf{3}\end{array}$ \\
\hline Total traffic & $18 \%$ & $9 \%$ \\
Total revenue & $22 \%$ & $8 \%$ \\
Total cost & $11 \%$ & $2 \%$ \\
\hline
\end{tabular}




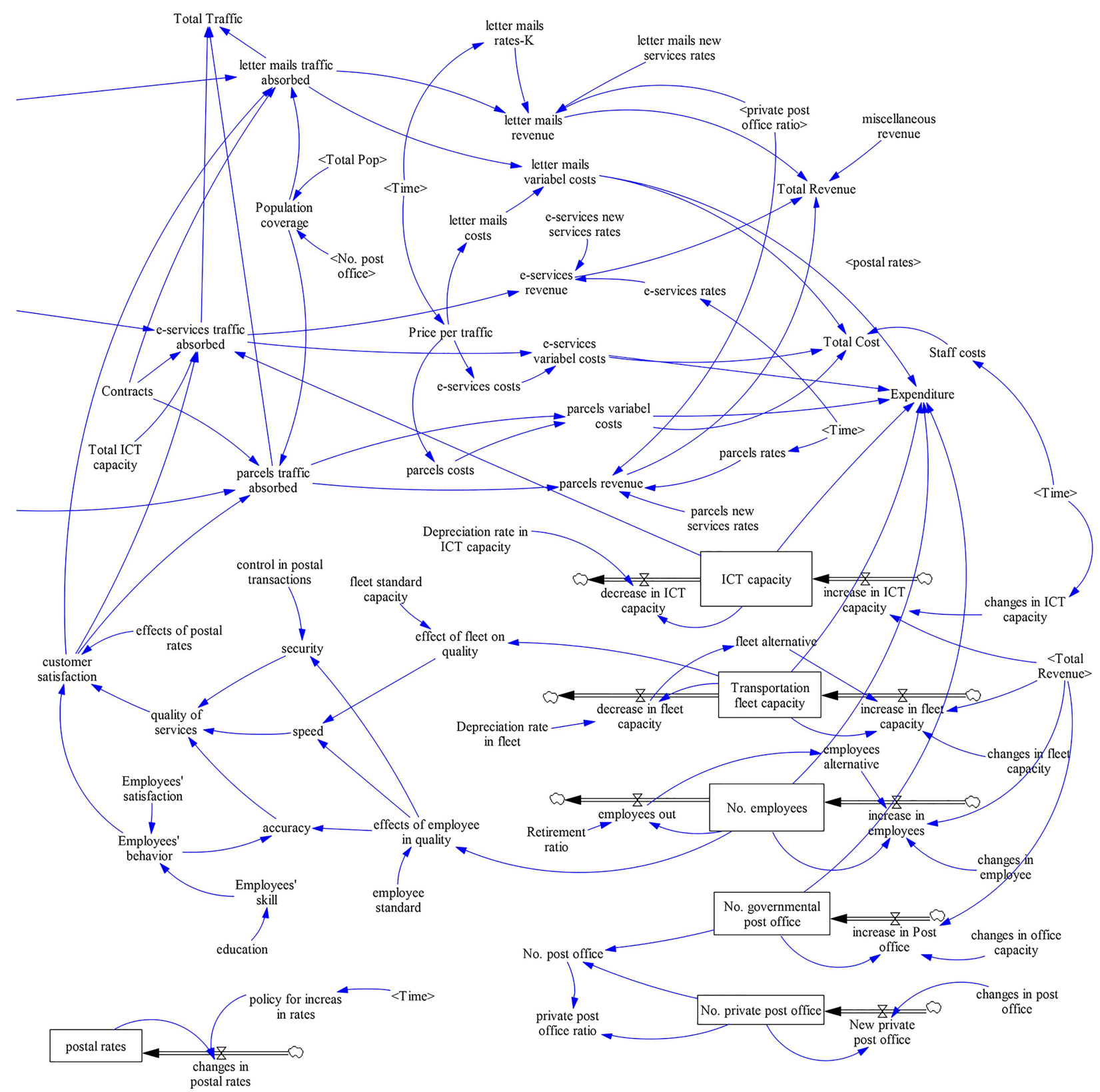

Figure 7. Mail demand absorbing structure (Figure 5(b)).

$$
M=\frac{100}{n} \sum_{t=1}^{n}\left|\frac{A_{t}-F_{t}}{A_{t}}\right|,
$$

where at time $t, A_{t}$ is the observation, $F_{t}$ the forecast of $A_{t}$, and $n$ the forecasting horizon.

To clarify the model's forecasting ability, a new dataset containing real data for the years 2017 and 2018 is gathered and this new historical data is compared to the simulated data. Table 4 represents these data along with MAPE errors.

This model is also applied at the provenance level to demonstrate the ability and applicability of the model at different levels. The MAPE errors of five provenances for key indicators are reported in Table 5.
The results show that the model can generate the behavior observed in other instances of the same system (Family member test [27]).

\section{Policy making}

According to the previous section, the developed SFD can be used to make preliminary predictions and forecast trends of indicators. Moreover, it can be a valuable tool for making policies and helping decisionmakers to make effective interventions. This is done by focusing on plausible events, either in inner or outer environment. In this study, scenario planning method is applied to develop scenarios which question the 


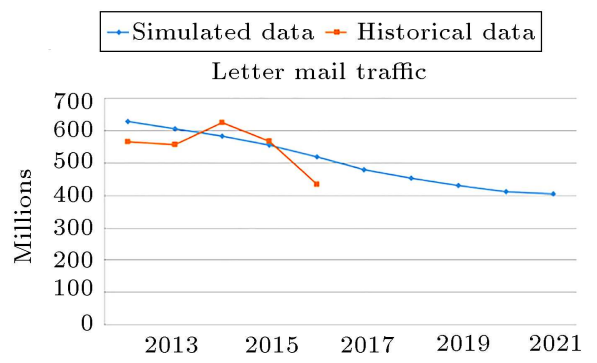

(a)

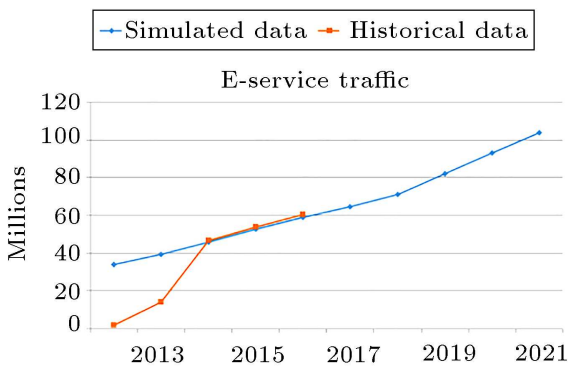

(c)

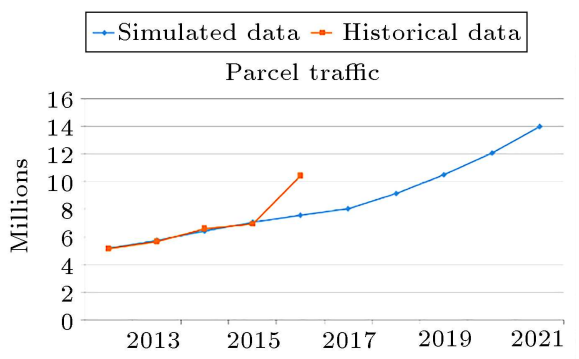

(b)

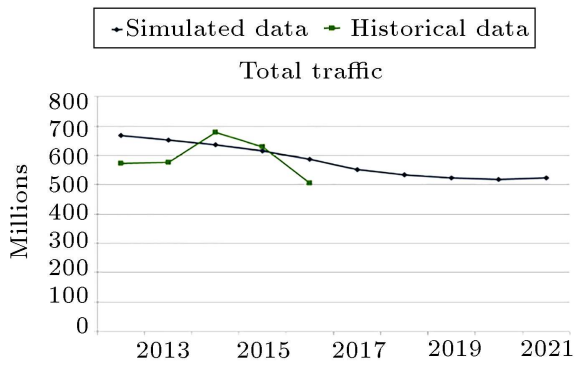

(d)

Figure 8. Simulated data vs. historical data for (a) letter mail traffic, (b) parcel traffic, (c) e-services traffic, and (d) total traffic.

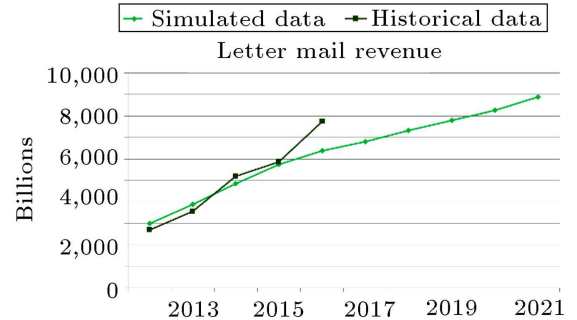

(a)

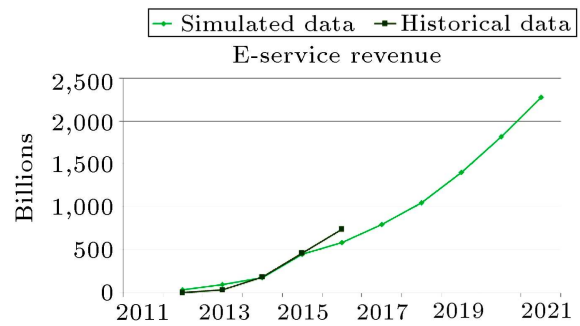

(c)

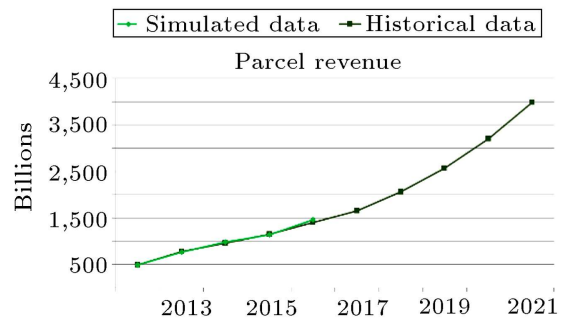

(b)

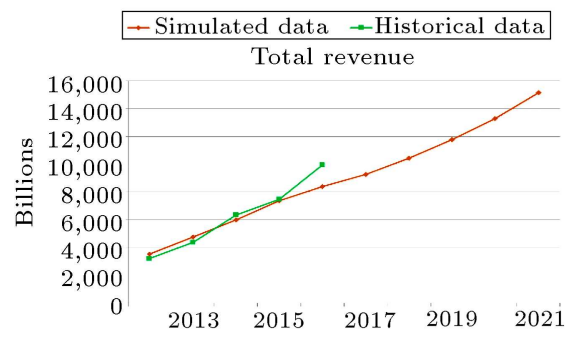

(d)

Figure 9. Simulated data vs. historical data for (a) letter mail revenue, (b) parcel revenue, (c) e-services revenue, and (d) total revenue.

assumptions and mental models (CLD) of experts. The two developed scenarios are as follows (these scenarios are developed based on expertise of key personnel in Iran Post Company and the most probable situations in near future):

1. Changes in postal rates and quality of services. In this scenario, seven situations could happen:

(1) Increase in postal rates and quality of services;

(2) Decrease in postal rates and quality of services;

(3) Increase in postal rates and decrease in quality of services;
(4) Decrease in postal rates and increase in quality of services;

(5) Increase in postal rates and no changes in quality of services;

(6) No changes in postal rates and increase quality of services;

(7) No changes in postal rates and quality of services (Baseline).

2. Absorbing $10 \%$ of e-service market share by new postal operator and (1) e-commerce increases by $10 \%$ compared to the baseline scenario, or (2) 
Table 4. Historical data vs. simulated data for 2017 and 2018.

\begin{tabular}{lcccccc}
\hline \multirow{2}{*}{ Indicator } & \multicolumn{2}{c}{$\mathbf{2 0 1 7}$} & & \multicolumn{2}{c}{$\mathbf{2 0 1 8}$} \\
\cline { 2 - 3 } & Historical data & Simulated data & & Historical data & Simulated data \\
\hline Total traffic $\left(10^{6}\right)$ & 492 & 552 & 489 & 534 & $10 \%$ \\
Total revenue $\left(10^{9}\right)$ & 9,582 & 9,254 & & 10,100 & 10,436 & $3 \%$ \\
Total cost $\left(10^{9}\right)$ & 10,836 & 9,073 & & 11,760 & 10,380 & $14 \%$ \\
\hline
\end{tabular}

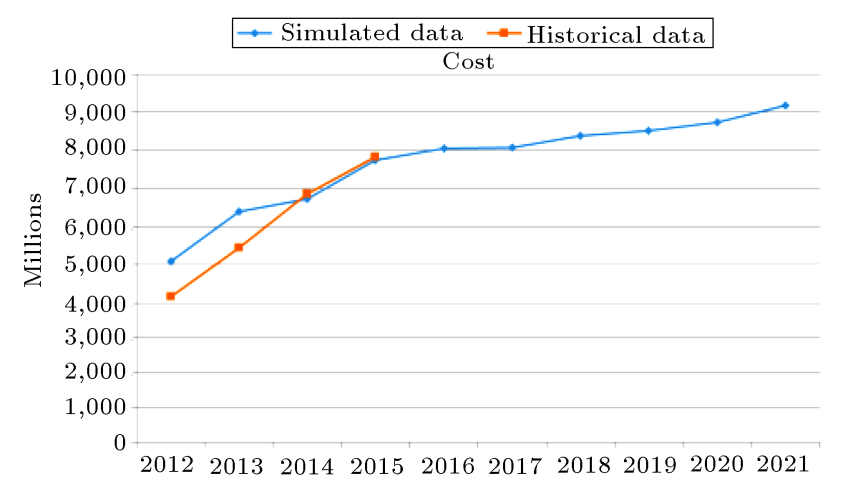

Figure 10. Simulated data vs. historical data in terms of cost.

Table 5. MAPE $(n=3)$ results for 5 proveniences.

\begin{tabular}{cccc}
\hline Provenance & $\begin{array}{c}\text { Total } \\
\text { traffic }\end{array}$ & $\begin{array}{c}\text { Total } \\
\text { revenue }\end{array}$ & $\begin{array}{c}\text { Total } \\
\text { cost }\end{array}$ \\
\hline ALB. & $12 \%$ & $8 \%$ & $10 \%$ \\
IL. & $17 \%$ & $12 \%$ & $13 \%$ \\
AZ.S. & $15 \%$ & $11 \%$ & $1 \%$ \\
AZ.G. & $6 \%$ & $6 \%$ & $8 \%$ \\
THE. & $12 \%$ & $10 \%$ & $3 \%$ \\
\hline
\end{tabular}

e-commerce decreases by $10 \%$ compared to the baseline scenario.

The results of simulations for these scenarios are reported based on performance indicators and are compared to the baseline scenario (business as usual), as reported in previous section.

\subsection{Changes in postal rates and quality of services}

In this scenario, seven situations could happen:

1. Increase in postal rates and quality of services $(\uparrow P$, $\uparrow Q)$;

2. Decrease in postal rates and quality of services $(\downarrow$ $P, \downarrow Q)$;

3. Increase in postal rates and decrease in quality of services $(\uparrow P, \downarrow Q)$;
4. Decrease in postal rates and increase in quality of services $(\downarrow P, \uparrow Q)$;

5. Increase in postal rates and no changes in quality of services $(\uparrow P, \sim Q)$;

6. No changes in postal rates and increase in quality of services $(\sim P, \uparrow Q)$;

7. No changes in postal rates and quality of services (Baseline).

Figure 11 presents the results of total traffic, total revenue, and total cost in comparison with the baseline scenario.

According to these figures, mail demands are more elastic to the quality of services than the price. That is, increase or no change in price does not have a large impact on total revenue, while increase in quality would increase total revenue. Thus, the main strategy of the company has to be for increasing the quality of services.

\subsection{Absorbing 10\% of e-service market share by the new operator}

In this scenario, emerging a new postal operator is analyzed and it is assumed that this operator will absorb $10 \%$ of e-service market share. Meanwhile, the e-commerce could increase, decrease or could be as usual. Thus, the following situations could happen:

1. Absorbing $10 \%$ of e-service market share by the new operator and $10 \%$ increase in e-commerce (new Op, $+10 \% \uparrow$ e-service);

2. Absorbing $10 \%$ of e-service market share by the new operator and 10\% decrease in e-commerce (new Op, $+10 \% \downarrow$ e-service);

3. Absorbing $10 \%$ of e-service market share by the new operator and no changes in e-commerce (new $\mathrm{Op}$ ).

Figure 12(a)-(c) shows the effects of the above situations on e-service traffic, e-service revenue, and total revenue in comparison with the baseline scenario.

As reported in the above figure, e-service traffic and revenue along with total revenue would decrease in the case of (New Op, $+10 \% \downarrow$ e-service) compared to the baseline scenario. In the case of (New Op, $+10 \% \uparrow$ 


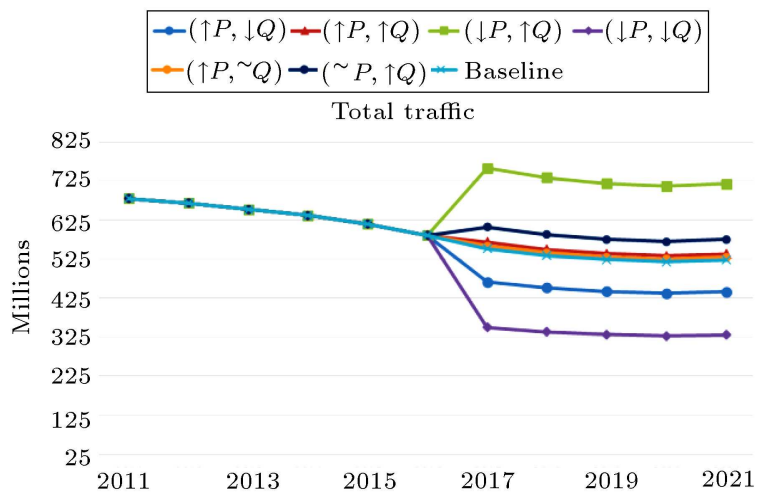

(a)

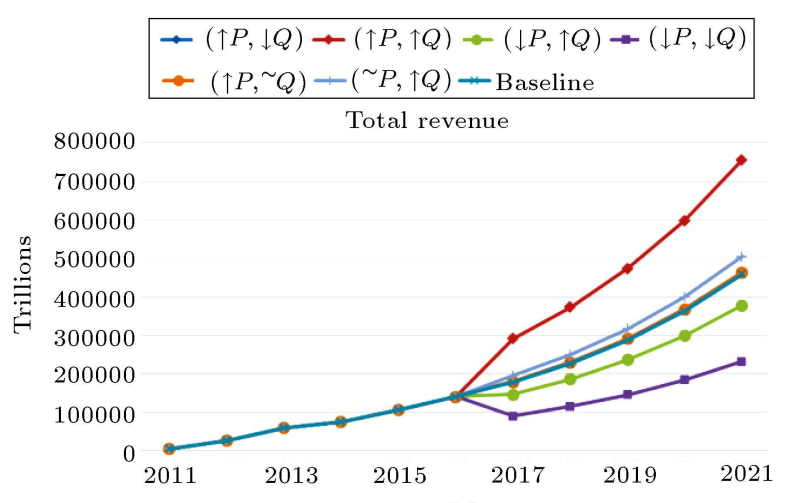

(b)

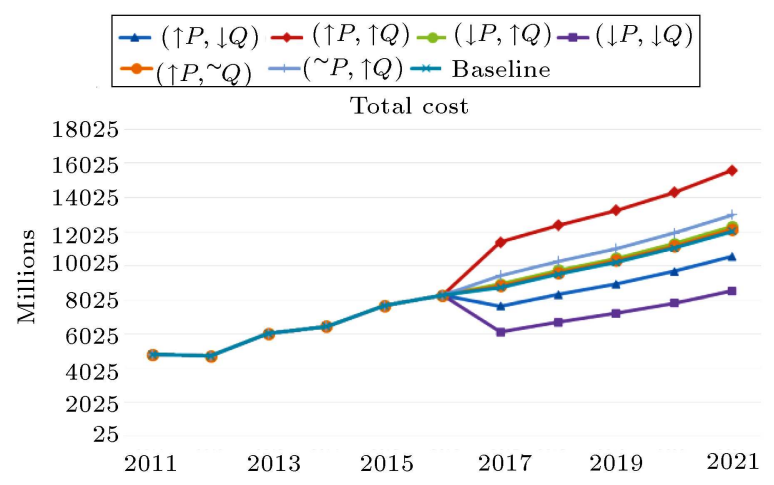

(c)

Figure 11. Results of total: (a) Traffic, (b) revenue, and (c) cost in comparison with baseline for the first scenario.

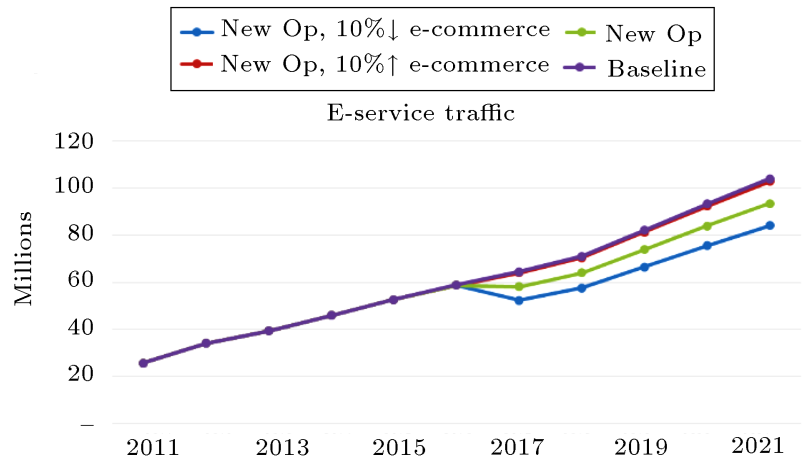

(a)

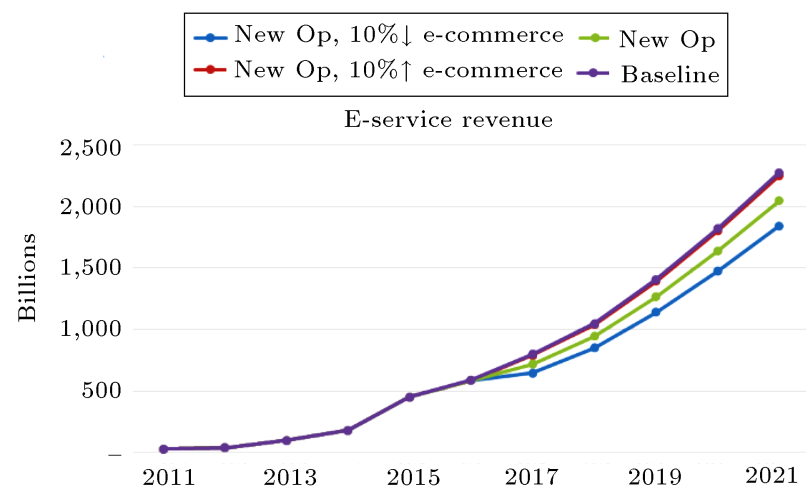

(b)

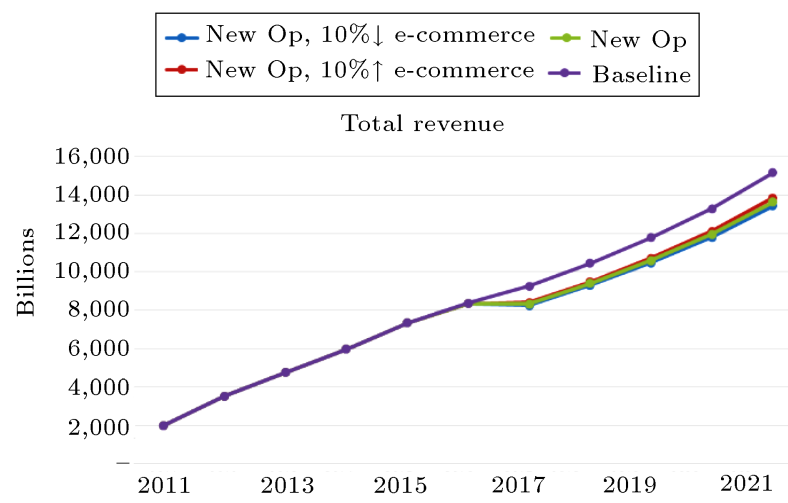

(c)

Figure 12. Results of (a) e-service traffic, (b) e-service revenue, and (c) total revenue for the second scenario. 


\section{Nast Company of I.R. Iran}

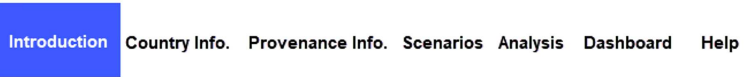

Delivering letter mails and parcels were the main activities in postal services and for more than 200 years, postal services have fulfilled their mission. However, the market needs and customers' needs and desires are changing rapidly. More specifically, aging, immigration, emerging new technologies and services along with emerging new postal operators (competitors) and changing in customers' desires have affected the postal environment. In these conditions, providing new services, allocating resources, estimating performance, planning for future, and making policies could be challenging. To overcome these challenges forecasting and predicting is essential.

To predict the future, various methods have been developed. Simulation is widely used method in dynamic situations and is used to understand and to estimate systems' real behavior over time. System Dynamic (SD) is a macro simulation and considers the system as a set of loops to determine its dynamics and to find dynamic behavior through time. This behavior is (re)created by tracking the changes in the values of stocks and flows over time and by mapping information transfers among them.

Understanding the Iran Post Company environment and forecasting postal services performance over the time is the main concern. In order to make the developed model more user friendly and more useful for companies CEOs, a web-based user interface is designed using python programming language and most important performance indicators, traffic, revenue, and cost, are analyzed using SD method.

Figure 13. First page of the designed dashboard.

e-service), e-service traffic and revenue are very close to those in the baseline scenario; however, as the new operator could absorb other services (letter mail and parcel), the total revenue would decrease. That is, emerging a new operator would decrease the total revenue and this would be less harmful if the e-commerce increases. Thus, the company has to concentrate on developing e-commerce and encouraging people to use the e-services.

\section{User Interface (UI)}

In order to make the developed model more user friendly and more useful for Companies CEO, a webbased UI is designed using Python programming language. Figure 13 demonstrates the first page of this dashboard. This page provides a summarized description.

The simulated data for postal performance are also reported in this dashboard (Figure 14).

Figure 15 is designed for policy making. In this page, by changing the values of variables, different scenarios could be formed and the results would appear against the baseline scenario (Figure 16).

\section{Conclusion}

Forecasting postal performance indicators and providing effective policy making tools for Iran Post Company are the main concerns in this paper. Various methods have been developed for these purposes. System dynamic is a macro simulation technique used to understand and model the dynamic behavior of a complex system through time. Using this approach and based on forecasting methodology, in the first step, the problem was defined and the important variables were identified and categorized into two categories: inner variables and outer variables. The inner variables were employed to develop the mail demand absorbing structure and the outer variables constructed the mail demand generating structure. Thus, two Causal-Loop Diagrams (CLDs) were developed and validated by expert panels. The needed data and information were then gathered and an Stock-to-Flow Diagram (SFD) was developed to simulate the behavior of indicators through time. The obtained results were evaluated using various methods. To help the decision-makers, two scenarios were also designed and the results indicate that the company has to increase the quality of services and concentrate on developing e-commerce. A User Interface (UI) was also designed using Python programming language to make the developed model more user friendly and more useful for Companies' CEO.

This paper shows that System Dynamic (SD) can be used as a proper approach to forecasting and making policies. In addition, it has some potential future works; for more realistic results, it is recommended that Geographic Information System (GIS) be integrated with SD and developing a web-based framework in the form of managerial dashboard could also provide organizational access to the obtained results.

\section{Acknowledgment}

This research was supported by a grant from Iran Post Company. The authors are grateful to Eng. Nasiri and Dr. Rahmati for his consultations and the experts 
N Post Company of I.R. Iran

Introduction Country Info. Provenance Info. Scenarios Analysis Dashboard Help Total traffic
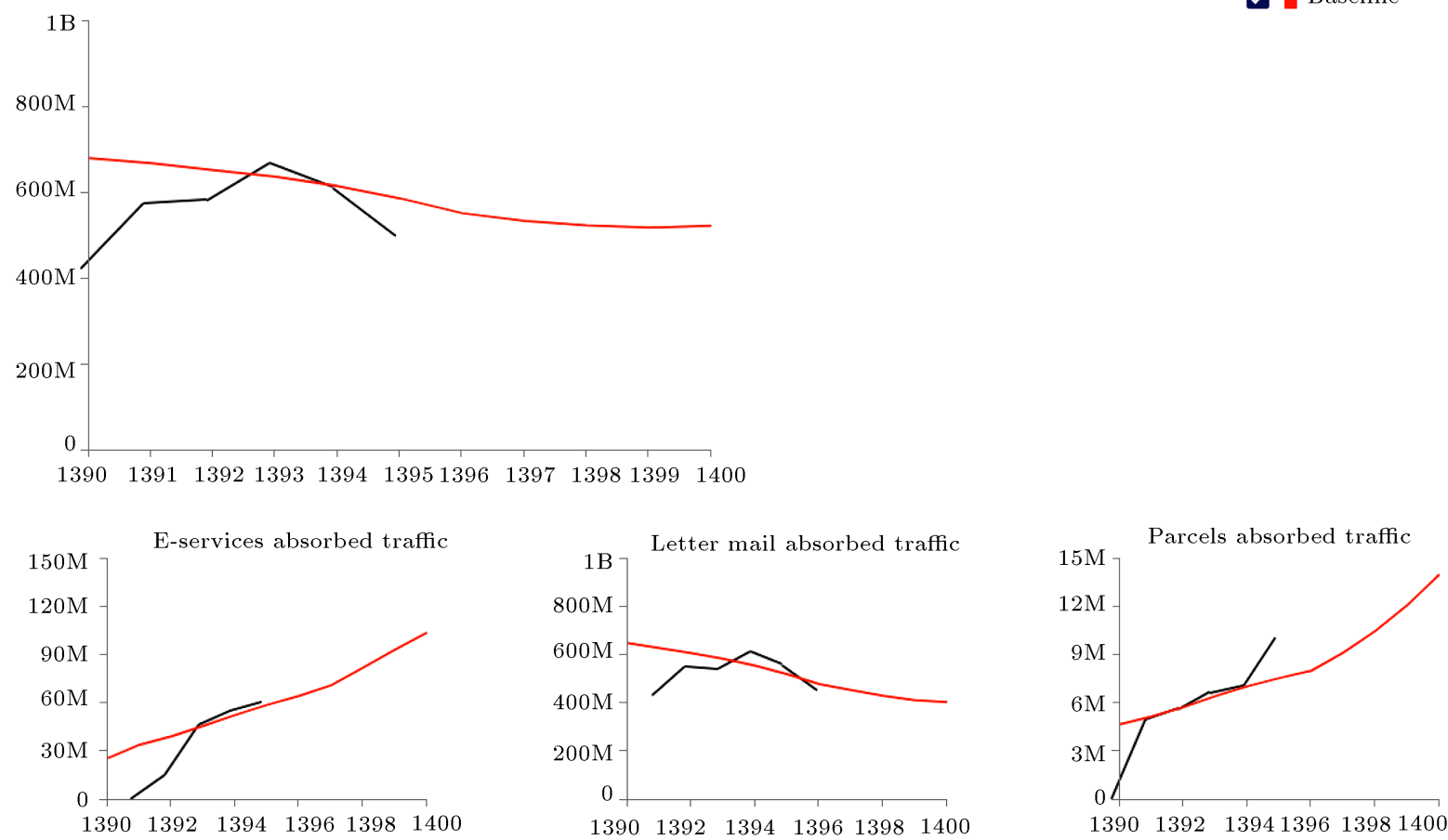

Figure 14. The simulated data for postal performance reported in the developed dashboard.

\section{N Post Company of I.R. Iran}

\section{Introduction Country Info. Provenance Info. Scenarios Analysis Dashboard Help \\ Inner Variables Outer Variables}

Initial values:

Economic growth $=0.04$

Student rate $=1.04$

Employment ratio $=0.32$

Inflation ratio for 5 years $=21.00$

ICT development ratio $=0.05$

ICT penetration rate $=0.17$

Economic growth

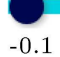

0.2

Student rate

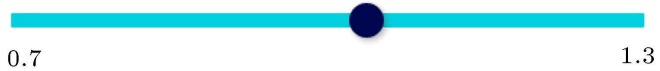

Employment ratio

0.2
Inflation ratio for 5 years

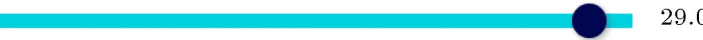

ICT development ratio

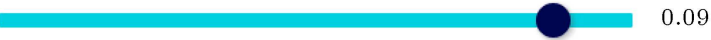

0

ICT penetration rate

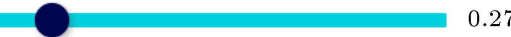

Reset

Name

Figure 15. Policy making in the developed dashboard by changing values of different variables. 
$[\mathrm{t}]$

\section{N Post Company of I.R. Iran}

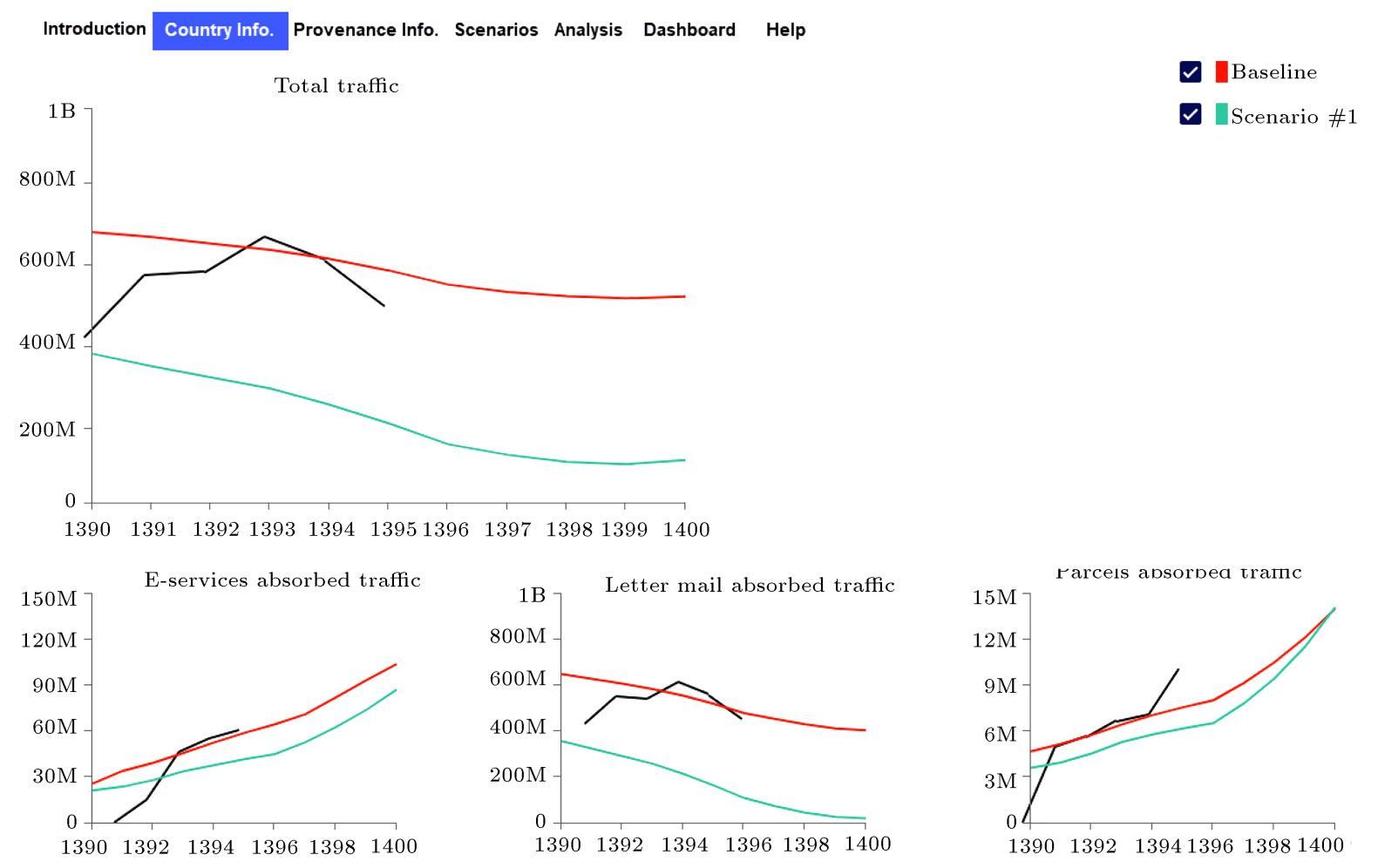

Figure 16. New scenario against baseline.

in Iran Post Company for their supports. Authors also thank the anonymous referees for their insightful suggestions and comments.

\section{References}

1. Matović, V. and Dobrodolac, M. "Forecasting the number of postal services in the region of south east Europe", 1st Int. Conf. Transp. Today's Soc., pp. 571579 (2016).

2. Qin, M., Li, Z., and Du, Z. "Red tide time series forecasting by combining ARIMA and deep belief network", Knowledge-Based Syst., 125, pp. 39-52 (2017).

3. Meade, N. and Islam, T. "Forecasting in telecommunications and ICT- A review", Int. J. Forecast., 31(4), pp. 1105-1126 (2015).

4. Cazals, C., Florens, J.P., Veruete-McKay, L., Soteri, S., and Rodriguez, F. "UK letter mail demand: a content-based time-series analysis using overlapping market survey statistical techniques", In Reinventing the Postal Sector in an Electronic Age, Edward Elgar Publishing (2011).

5. Odeck, J. and Welde, M. "The accuracy of toll road traffic forecasts: An econometric evaluation", Transp. Res. Part A Policy Pract., 101, pp. 73-85 (2017).

6. Cabral, J.de A., Legey, L.F.L., and Freitas Cabral, M.V.de "Electricity consumption forecasting in Brazil:
A spatial econometrics approach", Energy, 126, pp. 124-131 (2017).

7. Trinkner, U. and Grossmann, M., Forecasting ESubstitution and Mail Demand, Swiss Economics Working Paper (2006).

8. Voyant, C., Notton, G., Darras, C., Fouilloy, A., and Motte, F. "Uncertainties in global radiation time series forecasting using machine learning: The multilayer perceptron case", Energy, 125, pp. 248-257 (2017).

9. Farajpour, G. "Forecasting postage traffic using principal component analysis and artificial neural network", African J. Bus. Manag., 6(33), p. 9496 (2012).

10. Ostadi, B., Motamedi Sedeh, O., Husseinzadeh Kashan, A., and Amin-Naseri, M.R. "An intelligent model to predict the day-ahead deregulated market clearing price: a hybrid NN, PSO and GA approach", Sci. Iran., 26(6), pp. 3846-3856 (2019).

11. Wu, L., Zhang, K., Zhao, T. "Forecasting natural gas production and consumption using grey model with latent information function: The cases of China and USA", Sci. Iran., 28(1), pp. 386-394 (2021).

12. Xie, M., Wu, L., Li, B., and Li, Z. "A novel hybrid multivariate nonlinear grey model for forecasting the traffic-related emissions", Appl. Math. Model., 77(1), pp. 1242-1254 (2020). 
13. Şahin, U. "Forecasting of Turkey's greenhouse gas emissions using linear and nonlinear rolling metabolic grey model based on optimization", J. Clean. Prod., 239, p. 118079 (2019).

14. Leitner, S., Rausch, A., and Behrens, D.A. "Distributed investment decisions and forecasting errors: An analysis based on a multi-agent simulation model", Eur. J. Oper. Res., 258(1), pp. 279-294 (2017).

15. Sharma, P., Kulkarni, M.S., and Yadav, V. "A simulation based optimization approach for spare parts forecasting and selective maintenance", Reliab. Eng. Syst. Saf., 168(1), pp. 274-289 (2017).

16. Cazals, C., Florens, J.P., Rodriguez, F., and Soteri, S. "Forecast uncertainty in dynamic models: an application to the demand for mail", Compet. Regul. Post. Deliv. Sect., Edward Elgar Publishers, pp. 6373 (2008).

17. Phillips, P.C.B. "Laws and limits of econometrics", Econ. J., 113, p. 486 (2003).

18. Elsawah, S., Pierce, S.A., Hamilton, S.H., van Delden, H., Haase, D., Elmahdi, A., and Jakeman, A.J. "An overview of the system dynamics process for integrated modelling of socio-ecological systems: Lessons on good modelling practice from five case studies", Environ. Model. Softw., 93, pp. 127-145 (2017).

19. Suryani, E., Chou, S.-Y., Hartono, R., and Chen, C.H. "Demand scenario analysis and planned capacity expansion: A system dynamics framework", Simul. Model. Pract. Theory, 18(6), pp. 732-751 (2010).

20. Hu, B., Zhang, D., Ma, C., Jiang, Y., Hu, X., and Zhang, J. "Modeling and simulation of corporate lifecycle using system dynamics", Simul. Model. Pract. Theory, 15(10), pp. 1259-1267 (2007).

21. Georgiadis, P. "An integrated system dynamics model for strategic capacity planning in closed-loop recycling networks: A dynamic analysis for the paper industry", Simul. Model. Pract. Theory, 32(Supplement C), pp. 116-137 (2013).

22. Rafiei, H., Rabbani, M., and Hosseini, S.H. "Capacity coordination under demand uncertainty in a hybrid make-to-stock/make-to-order environment: A system dynamics approach", Sci. Iran., 21(6), pp. 2315-2325 (2014).

23. Heidarzadeh, S., Doniavi, A., and Solimanpur, M. "Development of supply chain strategy in Iranian automotive industry based on system dynamics and game theory", Sci. Iran., 24(6), pp. 3345-3354 (2017).

24. Langellier, B.A., Kuhlberg, J.A., Ballard, E.A., Slesinski, S.C., Stankov, I., Gouveia, N., Meisel, J.D., Kroker-Lobos, M.F., Sarmiento, O.L., Caiaffa, W.T., and Diez Roux, A.V. "Using community-based system dynamics modeling to understand the complex systems that influence health in cities: The SALURBAL study", Health Place, 60, p. 102215 (2019).

25. Gary, M.S., Kunc, M., Morecroft, J.D.W., and Rockart, S.F. "System dynamics and strategy", Syst. Dyn. Rev., 24(4), pp. 407-429 (2008).
26. "Iran Post Company", www.post.ir.

27. Sterman, J., Business Dynamics: Systems Thinking and Modeling for a Complex World, McGrawHill/Irwin (2000).

28. Makridakis, S.G., Wheelwright, S.C., and Hyndman, R.J., Forecasting: Methods and Applications, 3rd Edn., John Wiley \& Sons Ltd (1998).

29. Crew, M.A., Kleindorfer, P.R., and Campbell, J.I., Handbook of Worldwide Postal Reform, Edward Elgar Publishing (2009).

30. Crew, M.A. and Kleindorfer, P.R., Eds., Heightening Competition in the Postal and Delivery Sector, Edward Elgar Publishing Limited (2008).

31. Burt, G., Wright, G., Bradfield, R., Cairns, G., and Van Der Heijden, K. "The role of scenario planning in exploring the environment in view of the limitations of PEST and its derivatives", Int. Stud. Manag. Organ., 36(3), pp. 50-76 (2006).

32. Fildes, R. and Kumar, V. "Telecommunications demand forecasting- a review", Int. J. Forecast., 18(4), pp. 489-522 (2002).

33. Veruete-McKay, L., Soteri, S., Nankervis, J., and Rodriguez, F. "Letter traffic demand in the UK: An analysis by product and envelope content type", Rev. Netw. Econ., 10(3), pp. 1-10 (2011).

34. Anson, J. and Helble, M. "Postal economics and statistics for strategy analysis - the long view", In Development Strategies for the Postal Sector: An Economic Perspective, Universal Postal Union, Berne, Switzerland (2014).

35. Plum, M. "The challenge of electronic competition: empirical analysis of substitution effects on the demand for letter services", In Managing Change in the Postal and Delivery Industries, Springer, pp. 270-287 (1997).

36. Hyndman, R.J. and Koehler, A.B. "Another look at measures of forecast accuracy", Int. J. Forecast., 22(4), pp. 679-688 (2006).

\section{Biographies}

Marzieh Zarinbal is an Assistant Professor of Information Systems (IS) Research Group at Iranian Research Institute for Information Science and Technology (Irandoc). Her research interests include system modeling, intelligent systems, fuzzy logic, machine learning, image processing, and gamification. She has a $\mathrm{PhD}$ in Industrial Engineering from Amirkabir University of Technology (Tehran Polytechnic). She received her MSc degree in Industrial Engineering from Amirkabir University of Technology and holds a BSc degree in Industrial Engineering from Alzahra University. She is the author and co-author of some books and many papers and is an advisor for some $\mathrm{PhD}$ and Master theses. 
Hamidreza Izadbakhsh is an Assistant Professor of Industrial Engineering at Kharazmi University. His research interests include system modeling, simulation, quality control, and data science. He has a $\mathrm{PhD}$ in Industrial Engineering from Iran University of Science and Technology. He received his MSc degree in Industrial Engineering from University of Tehran and holds a BSc degree in Industrial Engineering from Amirkabir University of Technology (Tehran Polytechnic). He has completed several innovative projects in industry. He is the author and co-author of books and many papers and is an advisor for many $\mathrm{PhD}$ and master theses.

Salman Shahvali is currently $\mathrm{PhD}$ candidate at the Department of Industrial Management, Shahid Beheshti University, Tehran, Iran. He received BSc and MSc degrees from the School of Statistics, University of Isfahan and School of Industrial Engineering,
University of Tehran, respectively. His main research interests include system dynamics, decision-making under uncertainty, data analysis, and applied operations research. He has published several papers in journals and international conference proceedings.

Ramin Hosseinalizadeh has a $\mathrm{PhD}$ in Industrial Engineering from Kharazmi University. His interests lie in socioeconomic systems, sustainable development, energy systems, techno-economic analysis and planning, and system dynamics.

Fariba ZadehLabaf received the BS, MSc, and $\mathrm{PhD}$ degrees in Statistics (Search Design) at University of Isfahan. Her favorite work areas are design of experiments, sampling, and linear model. She is the author and co-author of many papers and is an advisor for some master theses in these fields. 